\section{Endoscopic treatment of recurrent bleeding from a portobiliary fistula with a fully covered self-expandable metal stent}

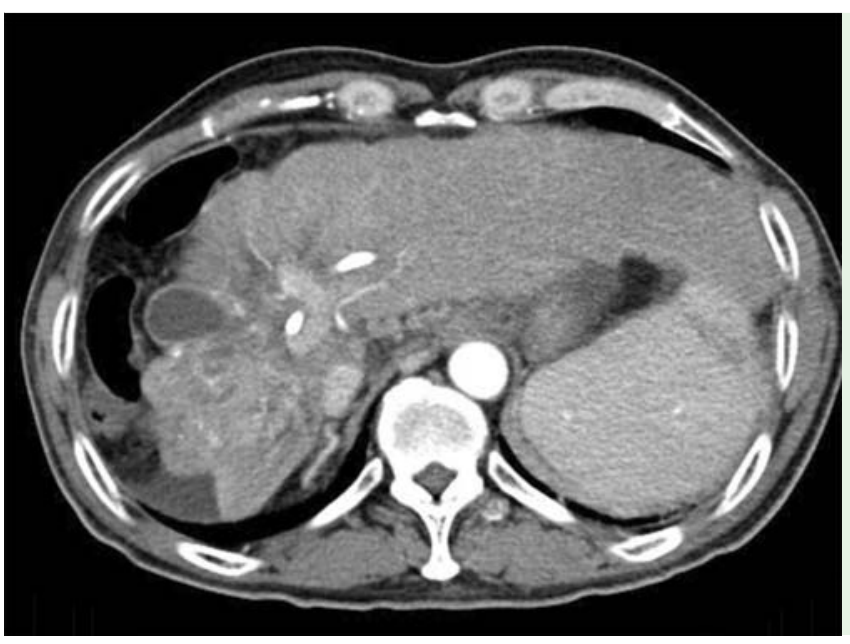

Fig. 1 Computed tomography (CT) scan showing infiltrative hepatocellular carci noma, liver cirrhosis, and atrophy of the right lobe, along with a previously inserted plastic stent.

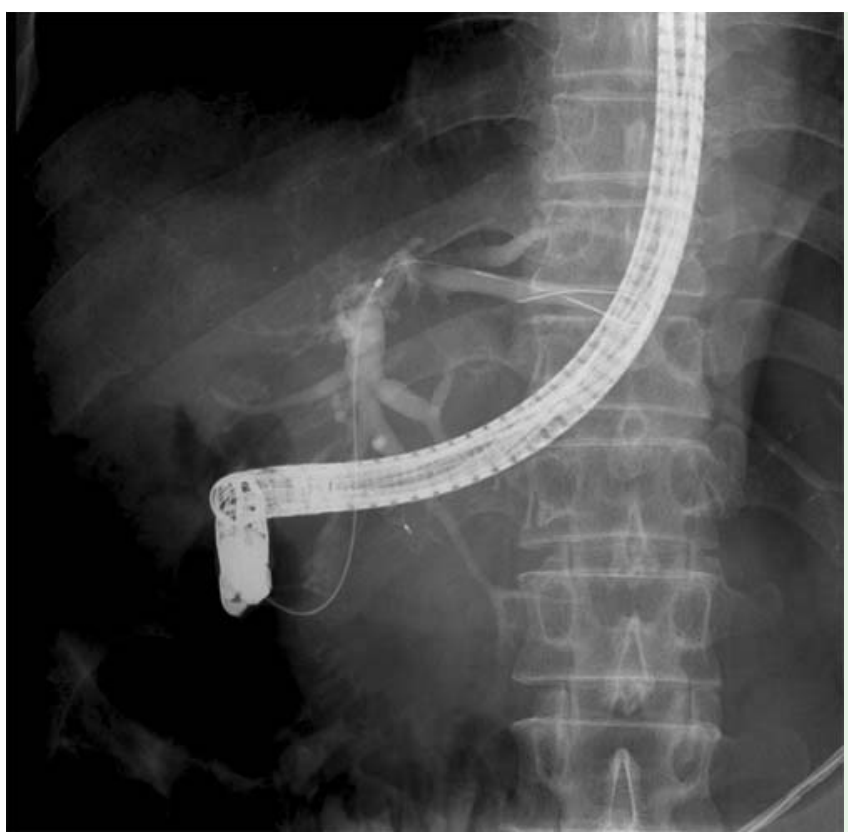

Fig. 2 Cholangiogram showing the hilar stricture.

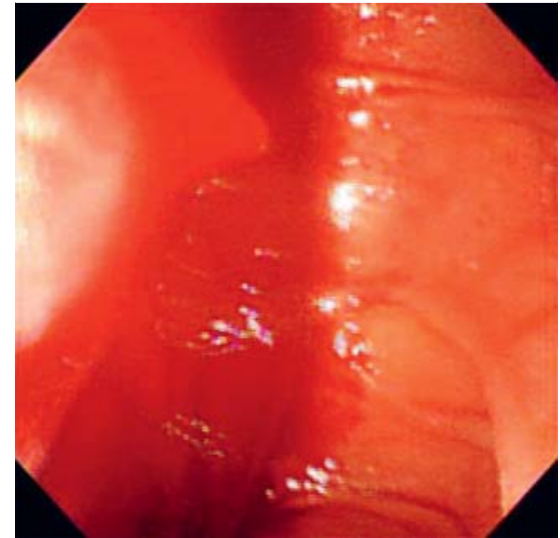

Fig. 3 Endoscopic image showing blood spurting from the ampulla after the previously inserted plastic stent had been removed.

Portobiliary fistula is a rare cause of hemobilia. It does not usually require any further intervention, but in some cases, persistent bleeding may result in bacteremia or hemodynamic compromise [1]. Previously this condition has been managed by percutaneous stent grafting or coil embolization [1 -3]. We report a successful case in which recurrent bacteremia and upper gastrointestinal bleeding due to a portobiliary fistula were managed using a fully covered self-expandable metal stent (FCSEMS).
A 55-year-old man with a diagnosis of hepatocellular carcinoma (HCC) and hepatitis B cirrhosis was admitted for a regular change of his hilar plastic stent. A biliary stent had first been placed at the hilum 6 months previously for management of obstructive jaundice caused by hilar invasion of HCC, and the stent had been regularly exchanged at 2-monthly intervals ( $\bullet$ Fig. 1 and $\bullet$ Fig. 2 ).

On admission, the patient was suffering from recurrent melena, and bacteremia. Endoscopic retrograde cholangiopancrea- tography (ERCP) was performed, and blood was observed oozing from the ampulla on endoscopy. After the previously inserted plastic stent was removed, the bleeding was suddenly exacerbated ( $\bullet$ Fig.3). Cholangiography revealed the hilar stricture and leakage of contrast dye from the hilar bile duct to the portal vein, suggesting a portobiliary fistula ( $\bullet$ Fig. 4 ). An endoscopic nasobiliary drain was placed in the left intrahepatic duct; however, melena and bacteremia continued. An ERCP was performed again, and an FCSEMS, $8 \mathrm{~mm}$ in diameter and $12 \mathrm{~cm}$ long (BONASTENT Biliary; Standard Sci Tech Inc., Seoul, Korea), was deployed at the B2 bile duct branch. A 10-Fr plastic stent was placed ahead at the anterior lateral branch (B3) of the intrahepatic bile duct to prevent obstructive cholangitis, which might have been induced by the FCSEMS ( $\bullet$ Fig.5). Following this procedure, the patient recovered from his recurrent bacteremia and hemobilia.

This case shows that endoscopic treatment using an FCSEMS can be considered as a treatment option for portobiliary fistula.

Endoscopy_UCTN_Code_CPL_1AK_2AD

Competing interests: None 


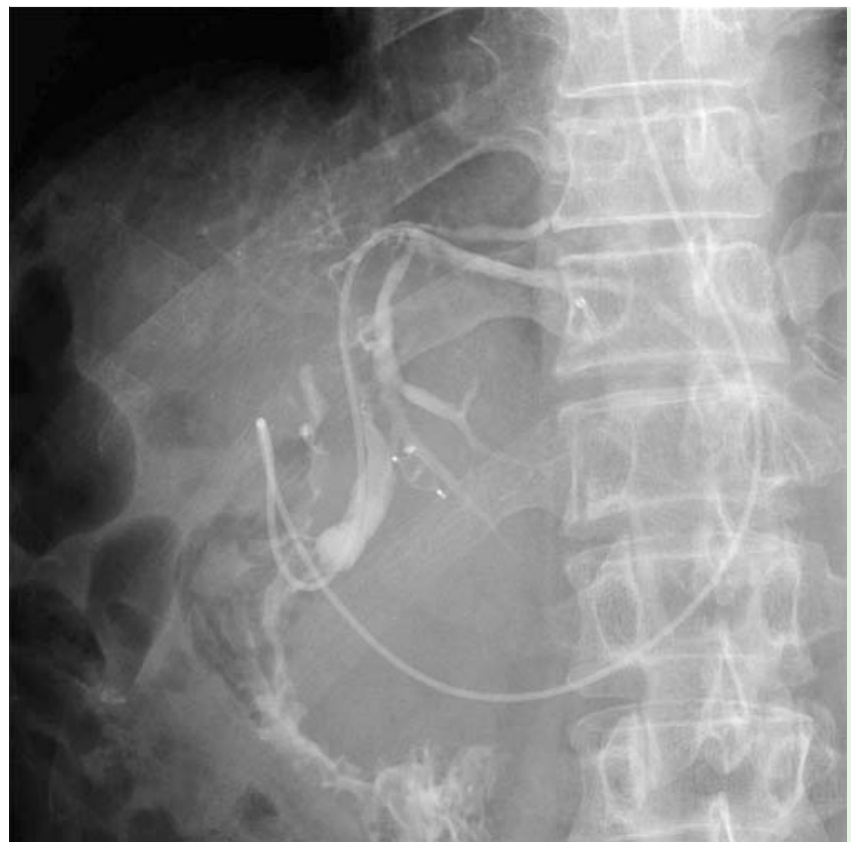

Fig. 4 Cholangiogram showing contrast filling defects at the hilar area due to leakage from the hilar bile duct to the portal vein.
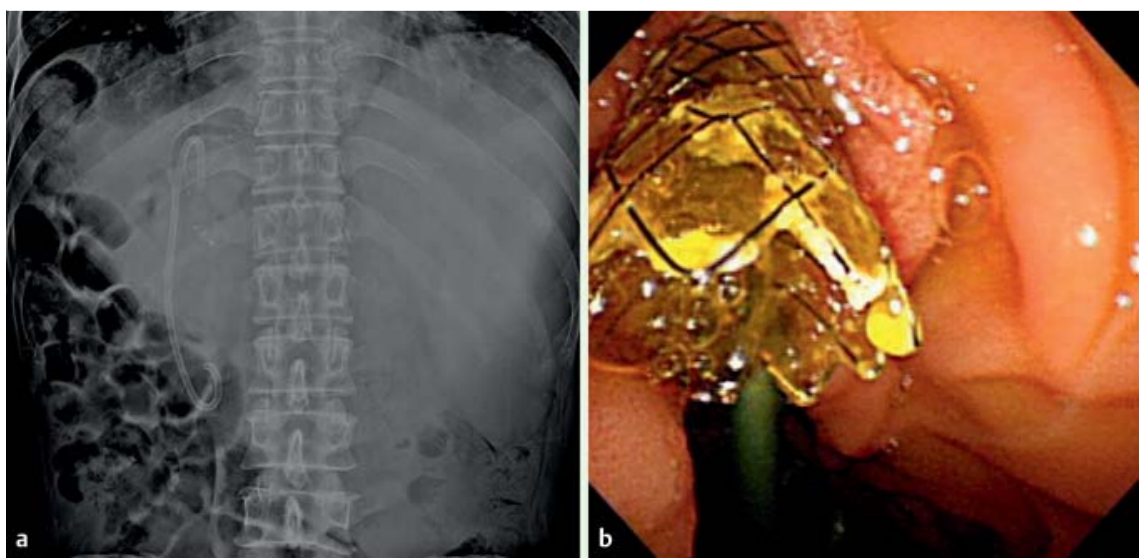

Fig. 5 Images of the fully covered self-expandable metal stent (FCSEMS) and plastic stent deployed in the intrahepatic bile duct, which led to the cessation of the hemobilia, on: a fluoroscopic view; b endoscopic view.
Hoonsub So, Tae Jun Song, Danbi Lee, Kyungwon Jung, Eun Jeong Gong, Dongwook Oh, Sang Soo Lee

Division of Gastroenterology, Department of Internal Medicine, University of Ulsan College of Medicine, Asan Medical Center, Seoul, South Korea

\section{References}

1 Peynircioglu B, Cwikiel W. Utility of stentgrafts in treatment of porto-biliary fistula. Cardiovasc Intervent Radiol 2006; 29: $1156-1159$

2 Chanyaputhipong J, Lo RH, Tan BS et al. Portobiliary fistula: successful transcatheter treatment with embolisation coils. Singapore Med J 2014; 55: e34 - e36

3 Lorenz JM, Zangan SM, Leef JA et al. Iatrogenic portobiliary fistula treated by stentgraft placement. Cardiovasc Intervent Radiol 2010; 33: 421-424

Bibliography

DOI http://dx.doi.org/

10.1055/s-0035-1569656

Endoscopy 2015; 47: E616-E617

(c) Georg Thieme Verlag KG

Stuttgart · New York

ISSN 0013-726X

\section{Corresponding author}

Tae Jun Song, MD, PhD

Division of Gastroenterology

Department of Internal Medicine

Asan Medical Center

88 , Olympic-Ro 43-Gil

Songpa-gu

Seoul 05505

South Korea

Fax: +82-2-4760824

drsong@amc.seoul.kr 